\title{
PBX1 Participated in Estrogen Mediated Bladder Cancer Progression and Chemo-Resistance through Affecting Estrogen Receptors
}

\section{Yang Zhao}

Yantai Affiliated Hospital of Binzhou Medical University

Jizhong Che

Yantai Affiliated Hospital of Binzhou Medical University

Aimin Tian

Yantai Affiliated Hospital of Binzhou Medical University

Gang Zhang

Yantai Affiliated Hospital of Medical University

Yankai Xu

Yantai Affiliated Hospital of Binzhou Medical University

Shuhang Li

Yantai Affiliated Hospital of Binzhou Medical University

Songlin Liu

Yantai Affiliated Hospital of Binzhou Medical University

Yinxu Wan ( $\nabla$ yingleiki@tom.com )

Yantai Affiliated Hospital of Binzhou Medical University https://orcid.org/0000-0002-3162-3265

\section{Research Article}

Keywords: bladder cancer, PBX1, estrogen receptors; chemo-resistance

Posted Date: August 24th, 2021

DOl: https://doi.org/10.21203/rs.3.rs-810980/v1

License: (c) (i) This work is licensed under a Creative Commons Attribution 4.0 International License.

Read Full License 


\section{Abstract}

Bladder cancer ( $\mathrm{BCa})$ is a common cancer associated with high morbidity and mortality worldwide. Pre-Bcell leukemia transcription factor 1 (PBX1) has been reported to be involved in tumor progression. The aim of the study was to explore the specific role of PBX1 in BCa and its underlying mechanisms. The relative expressions of PBX1 in muscle-invasive $\mathrm{BCa}$ tissues and cell lines were analyzed through RTqPCR and Western blotting. Kaplan-Meier analysis was used to analyze the relationship between PBX1 levels and survival status. Co-immunoprecipitation (CO-IP) and chromatin immunoprecipitation (ChIP)qPCR assay were adopted to verify the interaction between PBX1 and Estrogen receptors (ERs), and explore the ER-dependent genes transcription. The results shown that PBX1 was upregulated in invasive BCa patients and BCa cells, positively associated with tumor size, lymph node metastasis, distant metastasis and poorer survival status. Overexpression of PBX1 promoted cell growth, invasion, epithelialmesenchymal transition (EMT) process and cisplatin resistance in BCa cells, while the silence of PBX1 showed opposite effects. Further, PBX1 interacted with Estrogen receptors (ERs) and was required for the ER function. Overexpression of PBX1 aggravated the tumor-promoting effect of estrogen on BCa cells, while partially suppressed the inhibitory effects of ER antagonist AZD9496 on BCa cells. In summary, this study revealed that $\mathrm{PBX} 1$ participated in estrogen mediated $\mathrm{BCa}$ progression and chemo-resistance through binding and activating estrogen receptors. Hence, PBX1 may serve as a potential prognostic and therapeutic target for $\mathrm{BCa}$ treatment.

\section{Introduction}

Bladder cancer $(\mathrm{BCa})$ is a common cancer worldwide and associated with the high rates of morbidity and mortality [1]. Data from the World Health Organization (WHO) showed that there were about 549,393 new cases diagnosed and 199,922 deaths in the world in 2018 [2]. BCa develops into two distinct types: nonmuscle-invasive papillary tumor (70-80\%) and non-papillary (solid) muscle-invasive tumor (20-30\%) [1]. Commonly, patients with muscle-invasive bladder tumor accompanied with higher risks of metastasis and poor prognosis [3]. The five-year overall survival rate of muscle-invasive BCa patients is only $60 \%$ due to the distant metastasis and high recurrence rates [4]. Therefore, it is of great clinical significance to explore the molecular mechanism that drives the progression of muscle-invasive $\mathrm{BCa}$, which will help to develop more effective anticancer therapies.

PBX1 (Pre-B-cell leukemia transcription factor 1), a stem cell reprogramming factor, has a crucial role in the hematopoiesis and development of pancreas, spleen, kidney, urogenital tract, and skeleton [5-7]. It was first reported as a translocated proto-oncogene and exhibited an oncogenic potential in leukemia [8]. In addition, PBX1 was upregulated during the progressions of ovarian, melanoma, prostate, and breast cancers [9-13]. High expression level of PBX1 was negatively related to the survival of ovarian cancer patients, post-chemotherapy [9]. Enhanced PBX1 transcription could promote cell proliferation and metastasis in ERa-positive breast cancer and renal clear cell carcinoma [14, 15]. In addition, PBX1 was a key gene responsible for the bladder and kidney development, which was upregulated in fetal period and declined in adults, and the haploinsufficiency of PBX1 was regarded as a crucial factor causing 
congenital anomalies of the kidney and urinary tract [16]. However, the expression pattern and specific role of PBX1 in BCa remain unclear.

Recent evidence showed that women were more likely to develop an advanced tumor stages of BCa with nodal metastasis, although they had a lower BCa incidence compared with man [17]. Estrogen receptors (ERs) were found expressed in BCa tissues and cell lines [18, 19]. Estrogen receptor a (ERa) and Estrogen receptor $\beta$ (ER $\beta$ ) are two major isoforms of ER and was reported to play an important role in $B C a$ initiation and growth. ER $\beta$ could promote the growth and invasion ability of BCa cells [20], and induce cisplatin resistance in $\mathrm{BCa}$ [21]. ERa and $\mathrm{ER} \beta$ are located in the nucleus and mediate the genotype effect of estrogen through regulating the transcriptions of downstream target genes, such as MYC, CFOS, EGR3 and GREB1 [22, 23]. Higher expression of PBX1 was reported to be associated with the poor prognosis of ER-positive breast cancer patients [24]. Meanwhile, PBX1 was increased in the tissues of ERa-positive breast cancer patients during the metastatic progression [15]. Recent studies revealed that PBX1 was required for ER activity, and involved in the activation of $\operatorname{ER}[22,23]$.

In this study, we examined the expression of PBX1 in BCa patient tissues and cells, and its association with the clinicopathological characteristics of BCa patients. Next, the effects of PBX1 alteration on cell proliferation, apoptosis, and migration in $\mathrm{BCa}$ cells were measured. Furthermore, the underlying mechanism of PBX1 on the BCa cells was explored based on ER activation. Our study may provide a novel evidence for BCa therapy and prognosis.

\section{Materials And Methods}

\section{Patients and samples collection}

A total of 85 muscle-invasive BCa patients who underwent curative resection in Yantai Affiliated Hospital of Binzhou Medical University from 2012 to 2013 were recruited in this study. In line with the criteria of WHO, the specimens were confirmed by pathological specialists. The patients included were anonymous and had suffered cisplatin (CDDP) therapy before the surgery. According to their outcomes, relapse or not, we classified them into CDDP resistant and sensitive groups. The BCa tumor tissues and un-paired nontumor bladder tissues were harvested for analyzing the mRNA expression levels of PBX1. Five paired tumor tissues and non-tumor tissues were adopted to measure the protein expression of PBX1. Overall survival (OS) analysis was performed using the Kaplan-Meier method. This study was approved by he Institutional Review Board of Yantai Affiliated Hospital of Binzhou Medical University. Also, the whole experiment was under the guideline of Declaration of Helsinki. Informed consents were obtained from the corresponding patients before surgery.

\section{Cell lines}

BCa cell lines (J82, EJ, T24, UMUC3 and 5637) and a Human bladder epithelial immortalized cells (SVHUC-1) were obtained from Chinese Academy of Sciences Committee on Type Culture Collection cell bank (Shanghai, China). Cells were maintained in DMEM culture medium (GIBCO BRL, Gaithersburg, MD) 
with $10 \%$ fetal bovine serum (FBS, Invitrogen, Carlsbad, CA, USA). In line with the method described in previous study, the CDDP resistant T24 (T24 CR) and UMUC3 (UMUC3 CR) cells were established [25].

\section{RNA extraction and Realtime quantitative PCR (RT-qPCR)}

Total RNAs were isolated from BCa tissues and cells by using a Trizol kit (Qiagen, Valencia, CA). RT-qPCR was performed as described previously to examine mRNA expressions [26]. GAPDH was used as an internal control and each reaction was performed in triplicate. The primers used in this study was provided in Table 1.

\section{Cell transfection and treatments}

Full-length complementary DNA for PBX1 was cloned from the genomic DNA of BCa cells and ligated onto the sequences of pcDNA3.1 (+) vector which was purchased from Realgene (Nanjing, China). PBX1 siRNA (si-PBX1) and negative control siRNA (si-NC) were constructed by Genepharma Technology (Shanghai, China). Lipofectamine 3000 (Invitrogen, USA) was adopted for the transfection assay following the manufacturers' protocol. The transfection dose of overexpression vector and siRNAs were $0.5 \mu \mathrm{g}$ and $50 \mathrm{nM}$, respectively, and transfection procedure lasted for $48 \mathrm{~h}$.

CDDP drugs were purchased from MedChemExpress (Shanghai, China) and utilized in line with the protocol of manufacturers. The cultured cells were treated with different doses of CDDP and assessed cell viability at $24 \mathrm{~h}$ by using CCK-8 method. Finally, the drug sensitivity images and IC50 values for CDDP in every group were obtained on GraphPad Prism 8.0 software (GraphPad Software Inc., San Diego, USA).

\section{CCK-8 assay}

Cell viability was analyzed using a Cell Counting Kit-8 (CCK-8, Dojindo Laboratories, Kumamoto, Japan). In brief, cells were planted into 96-microwell plates with a density of 2000 cells/well. After transfection with overexpression vectors or siRNAs for 24,48 and $72 \mathrm{~h}$. The optical absorbance at $450 \mathrm{~nm}$ was detected using a plate reader (Thermo Fisher Scientific).

\section{Colony formation assay}

Cells were planted into 24-well plates with a density of 200 cells/well. Culture medium was replaced every two days. After cultured for two weeks, colonies were fixed and permeated using acetone/methanol (1:1, $\mathrm{v} / \mathrm{v}$ ) for $15 \mathrm{~min}$. Then colonies were stained with $0.5 \%(\mathrm{w} / \mathrm{v})$ crystal violet (Beyotime Biotechnology, Shanghai, China) for $15 \mathrm{~min}$. Following wash with distilled water and dry at room temperature, the colonies from five randomly selected fields were captured under an inverted phase contrast microscope, and colonies numbers were counted.

\section{Cell invasion assay}

Cell invasion ability was measured using a Transwell chamber (Corning, Corning, NY, USA) containing polycarbonate filters with $8.0 \mu \mathrm{m}$ pore size. Cells $\left(1 \times 10^{5}\right)$ and mixed with serum free medium. The cultured cells were seeded into the top chamber with a Matrigel-coated membrane. Complete medium 
was added into the lower chamber. After several hours of incubation at $37^{\circ} \mathrm{C}$, cells that invaded to the lower chamber were fixed and stained in $20 \%$ methanol and dye solution containing $0.1 \%$ crystal violet. The number of cells that had invaded was counted using an inverted microscope (Olympus, Tokyo, Japan).

\section{Western blotting}

Total proteins were extracted and quantified using the RIPA lysis buffer and a BCA Protein Assay kit (Beyotime, Shanghai, China). Then, proteins were separated by electrophoresis in 10\% SDS-PAGE and transferred onto nitrocellulose membranes. The membranes were blocked with $5 \%$ skim milk and incubated with specific primary antibodies $\left(4^{\circ} \mathrm{C}\right.$, overnight) and secondary antibodies $(2 \mathrm{~h}$, room temperature), in order. Image $\mathrm{J}$ Software was adopted for data analysis after developing with western ECL substrate (Share-bio, Shanghai, China).

\section{Co-immunoprecipitation (Co-IP) assay}

For Co-IP assay, protein samples were incubated with anti-PBX1 (1:200) agarose slurry (Sigma, USA) or control lgG for $2 \mathrm{~h}$ at $4^{\circ} \mathrm{C}$ [27]. The beads were collected by a centrifugation at $3000 \mathrm{rpm}$ for $5 \mathrm{~min}$. Then, the precipitated proteins were subjected to WB.

\section{Chromatin immunoprecipitation (ChIP)}

ChIP was performed using a ChIP assay kit (Active Motif, USA). T24 cells were crosslinked with 1\% formaldehyde and then the chromatin was sheared by micrococcal nuclease. The digested chromatin was incubated with ER antibody and $\lg G$ overnight at $4^{\circ} \mathrm{C}$. After the immunoprecipitation, protein $A / G$ plus agarose was added. Then, precipitates were washed, and purified DNA was subjected to qPCR detection. The specific primers used in this study were provided in Table 1.

\section{Data Analysis}

All data were shown as the mean \pm standard deviation (SD). Data analysis were performed using SPSS 18.0 software (IBM, NY, USA) and GraphPad Prism Version 7 (GraphPad Software). One-way ANOVA and $t$-test were performed to analyze the comparison between multiple groups and two groups. Overall survival (OS) analysis was performed using the Kaplan-Meier method. Statistical significance was defined when $p<0.05$.

\section{Results}

\section{PBX1 was upregulated in BCa patients and cells}

The expression pattern of PBX1 in BCa tumor tissues $(n=85)$ and paired non-tumor tissues $(n=53)$ were examined through RT-qPCR. As shown in Fig. 1A, the expression of PBX1 mRNA was significantly upregulated in BCa tumor tissues $(p<0.01)$. Kaplan-Meier analysis indicated that BCa patients with higher expression of PBX1 had significantly lower overall survival rate and outcome $(p=0.046$, Fig. 1B). 
The association between PBX1 expression and clinicopathologic characteristics of BCa patients were summarized in Table 2. Besides, the results showed that the level of PBX1 was positively associated with tumor size $(p=0.0326)$, lymph node metastasis $(p=0.0348)$ and distant metastasis $(p=0.0188)$.

Similarly, the protein expression of PBX1 was upregulated in BCa tissues compared with the normal ones (Fig. 1C). We compared the expression levels of PBX1 in SV-HUC-1 cells (a normal human bladder cell line) and BCa cell lines (J82, UMUC3, 5637, EJ, and T24) through Western blotting. The results indicated that $\mathrm{BCa}$ cells showed significantly higher expression of PBX1 (Fig. 1D).

\section{Effect of PBX1 alteration on the growth and apoptosis of BCa cells}

Overexpression vector of PBX1, and siRNA against PBX1 were transfected into T24 and UMUC3 cell lines. As shown in Fig. 2A-C, the expression of PBX1 mRNA and protein were markedly increased in ov-PBX1 transfected T24 and UMUC3 cell lines, and decreased in si-PBX1 transfected T24 and UMUC3 cell lines (Fig. 2A-C). Next, the results showed that the overexpression of PBX1 significantly promoted the cell proliferation and colony formation ability of T24 and UMUC3 cell lines (Fig. 2D-G). Meanwhile, the silence of PBX1 suppressed the growth of T24 and UMUC3 cells (Fig. 2D-G), and induced cell apoptosis in T24 and UMUC3 cells, while PBX1 overexpression showed no effect on cell apoptosis (Fig. 2H-J).

\section{Effect of PBX1 alteration on the invasion and epithelial- mesenchymal transition (EMT) activity of BCa cells}

Next, overexpression of PBX1 was found to greatly promote the invasion ability of T24 and UMUC3 cells, while inhibition of PBX1 has the opposite effect (Fig. 3A and B). EMT biomarkers, E-cadherin, N-cadherin, Vimentin, fibronectin and Snail, were analyzed through Western blotting. The results showed that the expression of E-cadherin was decreased in T24 cells after overexpression of PBX1 (Fig. 3C). In contrast, the expressions of $\mathrm{N}$-cadherin, Vimentin and fibronectin were markedly increased in T24 cells following upregulating PBX1, while si-PBX1 showed the opposite effects on the expressions of EMT biomarkers (Fig. 3C). However, the expression of Snail did not affect by PBX1 alterations in T24 cells (Fig. 3C).

\section{Pbx1 Regulated Chemo-resistance Of Bca Cells}

To illustrate the correlation between PBX1 alteration and CDDP resistance of $\mathrm{BCa}$, we first evaluated the expression profile of PBX1 in patients' tissues. As shown in Fig. 4A, PBX1 expression level was dramatically elevated in CDDP-resistant BCa tissues. Compared with normal T24 and UMUC3 cells, the resistant type of them presented significant upregulation in PBX1 expression (Fig. 4B). Also, we found that PBX1 silence decreased the promoted CDDP resistances and increased IC50 values in both T24 CR and UMUC3 CR cells (Fig. 4C and 4D). The expressions biomarkers of drug-resistance, P-gp and MRP1 [28], were increased in CR cells and depressed by PBX1 inhibition (Fig. 4E). 


\section{PBX1 mediated the ER function}

It has been reported that targeting to the corresponding pathway of anti-estrogen strategy emerged as a novel promising preclinical way for $\mathrm{BCa}$ [29]. Hence, our study explored the role of PBX1 in regulating ER function via measuring the ER-dependent gene transcriptions in T24 cells. We found that PBX1 overexpression or inhibition both made no significant effect on ERa and ER $\beta$ expression (Fig. 5A). The CoIP assay showed that endogenous PBX1 interacted with endogenous ERa and ER $\beta$ in T24 cells (Fig. 5B). Previous studies indicated that ER could bind with the enhancer region of EGR3, cFOS and myelocytomatosis proto-oncogene $(M Y C)$, promoted their transcription [22]. In this study, the silence of PBX1 suppressed the binding of ER to the enhancer of EGR3, CFOS and MYC in T24 cells (Fig. 5C). Meanwhile, inhibiting PBX1 suppressed the transcription of EGR3, CFOS and MYC induced by estrogen (E2) (Fig. 5D). Next, we found that the overexpression of PBX1 facilitated the binding of ER in the enhancer region of EGR3, CFOS and MYC and promoted their transcription (Fig. 6A and B). Estrogen (E2) further promoted the transcriptions of EGR3, CFOS and MYC in ov-PBX1 transfected T24 cells (Fig. 6B). These results suggested that $\mathrm{PBX} 1$ was required for ER function.

\section{Effect of PBX1 overexpression on E2 or ER antagonist treated T24 cells}

As shown in Fig. 7, estrogen (E2) treatment significantly promoted the proliferation, colony formation, cell invasion and CDDP resistance of T24 cells, while ER antagonist, AZD9496, effectively suppressed the proliferation, colony formation, and cell invasion of T24 cells, and induced cell apoptosis. Next, the results showed that the silence of PBX1 suppressed the promoted effects of E2 on T24 cell proliferation, colony formation and invasion, while overexpression of PBX1 facilitated the promotion of E2 on T24 cells and partially suppressed the inhibitory effect of AZD9496 on T24 cells (Fig. 7A-D).

\section{Discussion}

In this study, we found that PBX1 was upregulated in tumor tissues of muscle-invasive BCa patients and BCa cell lines. Meanwhile, high expression level of PBX1 was positively related to tumor size, lymph node metastasis, distant metastasis and poorer survival status of muscle-invasive BCa patients. Besides, PBX1 mediated the growth, EMT progress, invasion ability and chemo-resistance of BCa cells. EMT is a necessary process in cancer metastasis, it promoted the BCa metastasis and recurrence [30]. Gugnoni et al. indicated that inducing the attenuation of EMT progress by $\mathrm{CDH} 6$ down-regulation dramatically depressed the metastatic behavior of papillary thyroid carcinomas [31]. Another study demonstrated that tumor-associated neutrophils secreted IL-17a and stimulated the EMT feature of gastric cancer cells leading to tumor malignant progression [32]. Consistent to our findings, it has been reported that PBX1 was involved in the EMT process of esophageal cancer and non-small cell lung adenocarcinoma via collaboration with ZEB2 and PREP1 [33,34]. These results suggested that PBX1 may participated in BCa progression and may serve as a new prognostic and therapeutic target. 
Previous studies revealed that PBX1 interacted with ER and promoted ER activation in breast cancer inducing the promoted metastatic progression in ERa-positive breast cancer patients [22, 23]. In our study, PBX1 showed no obvious effect on the expression of ERa and ER $\beta$ in T24 cells, but interacted with both ERa and ER $\beta$. Deeply consulting the regulatory mechanism, we found that the inhibition of PBX1 suppressed the recruitment of ER to the enhancer of EGR3, CFOS and MYC in T24 cells. Evidence indicated that EGR3, cFOS and MYC were served as the target of ER transcription [35, 23]. In addition, cFOS and $M Y C$ were discovered to be oncogenes during BCa development, involving the regulations of cell proliferation, differentiation and invasion [36,37]. These results indicated that PBX1 was required for the post-transcriptional regulation of ER activity in BCa cells.

It is convinced that BCa incidence was higher in man than in women, but female BCa patients exhibited advanced TNM stage, shorter survival time and poor prognosis [17, 38, 39]. Accumulated evidence indicated that estrogens promoted BCa tumorigenesis $[40,41]$. The function of estrogens was mediated by its multiple receptors, including ERa and $\operatorname{Er} \beta$ [38]. The agonists of ERa and ER BCa cell proliferation $[20,42]$. Meanwhile, antiestrogens suppressed BCa cell growth, in vitro and in vivo $[43,44]$. Consistent with previous studies, our study found that estrogen promoted cell proliferation and migration, while ER antagonist AZD9496 suppressed cell proliferation and migration, induced cell apoptosis in T24 cells. Besides, our study found that PBX1 aggravated estrogen-induced cell growth and invasion, while partially weakened the inhibitory effect of ER antagonist on cell growth and invasion of BCa cells. This may be due to the carcinogenesis of estrogens was depended on its receptors, while PBX1 was required for the ER activity in BCa cells.

CDDP is a largely used tumor chemotherapy drug in clinic that exerts anti-cancer activity by formatting inter- and intra-strand DNA adducts $[45,46]$. Research data presented that $50 \% \sim 70 \%$ patients received therapeutic responses after CDDP-based treatment [47]. However, a tough issue occurred in the following therapy progression, in which tumor acquired a resistance to CDDP causing a high possibility of relapse [48]. Deeply efforts devoting on the potential mechanism of chemo-resistance might hold a great importance for solving the bottleneck of BCa therapy. Our research indicated that PBX1 was associated with the CDDP resistance of BCa patients and knockdown of PBX1 effectively promoted drug sensitivity of BCa cells via affecting ER signaling. Previously, PBX1 had been proved to be involved in the development of ovarian cancer chemo-resistance [49]. Takuro et al. discovered that tamoxifen modulated estrogen-mediated ER signaling pathway to enhance the drug sensitivity of BCa cells to CDDP [50], which greatly supported our findings.

PBX1 was upregulated in tumor tissues of muscle-invasive BCa patients and associated with tumor size, lymph node metastasis, distant metastasis and poorer survival status. PBX1 mediated BCa cell growth, EMT processes, invasion, cell apoptosis and CDDP resistance. In addition, PBX1 interacted with ERa and $E R \beta$, and was required for ER function. Overexpression of PBX1 aggravated the tumor-promoting effect of E2 on T24 cells and partially suppressed the inhibitory effect of AZD9496. Hence, it is suggested that PBX1 participated in BCa progression and chemo-resistance through binding and activation estrogen receptors. This study provided a new therapeutic target for muscle-invasive BCa. 


\section{Declarations}

\section{Funding:}

None

\section{Compliance with ethical standards}

Conflict of Interest The authors declare that they have no conflict of interest.

Ethical approval All the patients, diagnosed and treated at Yantai Affiliated Hospital of Binzhou Medical University, provided written informed consents. The whole study conformed to the Helsinki Declaration and the Health Guide for the Care and Use of Laboratory Animals (National Institutes), and obtained approvals the Institutional Research Ethic Committee and the Animal Ethical Committee of Yantai Affiliated Hospital of Binzhou Medical University.

Informed consent Informed consents were obtained from every patient included in this study.

Data Availability The datasets used and/or analyzed during the current study are available from the corresponding author on reasonable request.

Author contributions Yang Zhao and Yinxu Wanwrote the main manuscript text, Songlin Liu, Shuhang Li and Jizhong Che prepared figures 1-3. Gang Zhang,Yankai Xu and Aimin Tianprepared figures 4. All authors reviewed the manuscript.

\section{References}

\section{References}

1. Sanli O, Dobruch J, Knowles MA, Burger M, Alemozaffar M, Nielsen ME, Lotan Y (2017) Bladder cancer. Nature reviews Disease primers 3(1):1-19

2. Bray F, Ferlay J, Soerjomataram I, Siegel RL, Torre LA, Jemal A (2018) Global cancer statistics 2018: GLOBOCAN estimates of incidence and mortality worldwide for 36 cancers in 185 countries. CA Cancer J Clin 68(6):394-424. doi:10.3322/caac.21492

3. Dy GW, Gore JL, Forouzanfar MH, Naghavi M, Fitzmaurice C (2017) Global burden of urologic cancers, 1990-2013. European urology 71(3):437-446

4. Soloway MS (2013) Bladder cancer: lack of progress in bladder cancer-what are the obstacles? Nature reviews Urology 10(1):5

5. Ferraz-de-Souza B, Martin F, Mallet D, Hudson-Davies RE, Cogram P, Lin L, Gerrelli D, Beuschlein F, Morel Y, Huebner A (2009) CBP/p300-interacting transactivator, with Glu/Asp-rich C-terminal domain, 2 , and pre-B-cell leukemia transcription factor 1 in human adrenal development and disease. The Journal of Clinical Endocrinology Metabolism 94(2):678-683 
6. Schnabel CA, Selleri L, Cleary ML (2003) Pbx1 is essential for adrenal development and urogenital differentiation. Genesis 37(3):123-130

7. Teoh PH, Shu-Chien AC, Chan WK (2010) Pbx1 is essential for growth of zebrafish swim bladder. Developmental dynamics: an official publication of the American Association of Anatomists 239(3):865-874

8. Kamps MP, Look AT, Baltimore D (1991) The human $t(1 ; 19)$ translocation in pre-B ALL produces multiple nuclear E2A-Pbx 1 fusion proteins with differing transforming potentials. Genes Dev 5(3):358-368

9. Jung J-G, Shih I-M, Park JT, Gerry E, Kim TH, Ayhan A, Handschuh K, Davidson B, Fader AN, Selleri L (2016) Ovarian cancer chemoresistance relies on the stem cell reprogramming factor PBX1. Cancer research 76(21):6351-6361

10. Shiraishi K, Yamasaki K, Nanba D, Inoue H, Hanakawa Y, Shirakata Y, Hashimoto K, Higashiyama S (2007) Pre-B-cell leukemia transcription factor 1 is a major target of promyelocytic leukemia zincfinger-mediated melanoma cell growth suppression. Oncogene 26(3):339-348

11. Okada S, Irié T, Tanaka J, Yasuhara R, Yamamoto G, Isobe T, Hokazono C, Tachikawa T, Kohno Y, Mishima K (2015) Potential role of hematopoietic pre-B-cell leukemia transcription factor-interacting protein in oral carcinogenesis. Journal of Oral Pathology Medicine 44(2):115-125

12. Magnani L, Ballantyne EB, Zhang X, Lupien M (2011) PBX1 genomic pioneer function drives ERa signaling underlying progression in breast cancer. PLoS genetics 7 (11)

13. Kikugawa T, Kinugasa Y, Shiraishi K, Nanba D, Nakashiro Ki, Tanji N, Yokoyama M, Higashiyama S (2006) PLZF regulates Pbx1 transcription and Pbx1-HoxC8 complex leads to androgen-independent prostate cancer proliferation. Prostate 66(10):1092-1099

14. Wei X, Yu L, Li Y (2018) PBX1 promotes the cell proliferation via JAK2/STAT3 signaling in clear cell renal carcinoma. Biochem Biophys Res Commun 500(3):650-657. doi:10.1016/j.bbrc.2018.04.127

15. Magnani L, Patten DK, Nguyen VT, Hong SP, Steel JH, Patel N, Lombardo Y, Faronato M, Gomes AR, Woodley L, Page K, Guttery D, Primrose L, Fernandez Garcia D, Shaw J, Viola P, Green A, Nolan C, Ellis IO, Rakha EA, Shousha S, Lam EW, Győrffy B, Lupien M, Coombes RC (2015) The pioneer factor PBX1 is a novel driver of metastatic progression in ERa-positive breast cancer. Oncotarget 6(26):2187821891. doi:10.18632/oncotarget.4243

16. Le Tanno P, Breton J, Bidart M, Satre V, Harbuz R, Ray PF, Bosson C, Dieterich K, Jaillard S, Odent S, Poke G, Beddow R, Digilio MC, Novelli A, Bernardini L, Pisanti MA, Mackenroth L, Hackmann K, Vogel I, Christensen R, Fokstuen S, Béna F, Amblard F, Devillard F, Vieville G, Apostolou A, Jouk PS, GuebreEgziabher F, Sartelet $\mathrm{H}$, Coutton C (2017) PBX1 haploinsufficiency leads to syndromic congenital anomalies of the kidney and urinary tract (CAKUT) in humans. J Med Genet 54(7):502-510. doi:10.1136/jmedgenet-2016-104435

17. Dobruch J, Daneshmand S, Fisch M, Lotan Y, Noon AP, Resnick MJ, Shariat SF, Zlotta AR, Boorjian SA (2016) Gender and Bladder Cancer: A Collaborative Review of Etiology, Biology, and Outcomes. Eur Urol 69(2):300-310. doi:10.1016/j.eururo.2015.08.037 
18. Kauffman EC, Robinson BD, Downes M, Marcinkiewicz K, Vourganti S, Scherr DS, Gudas LJ, Mongan NP (2013) Estrogen receptor- $\beta$ expression and pharmacological targeting in bladder cancer. Oncol Rep 30(1):131-138. doi:10.3892/or.2013.2416

19. Bernardo C, Santos J, Costa C, Tavares A, Amaro T, Marques I, Gouveia MJ, Félix V, Afreixo V, Brindley PJ, Costa JM, Amado F, Helguero L, Santos LL (2020) Estrogen receptors in urogenital schistosomiasis and bladder cancer: Estrogen receptor alpha-mediated cell proliferation. Urol Oncol 38(9):738.e723.

-738.e735

. doi:10.1016/j.urolonc.2020.04.022

20. Ou Z, Wang Y, Chen J, Tao L, Zuo L, Sahasrabudhe D, Joseph J, Wang L, Yeh S (2018) Estrogen receptor $\beta$ promotes bladder cancer growth and invasion via alteration of miR-92a/DAB2IP signals. Exp Mol Med 50(11):1-11. doi:10.1038/s12276-018-0155-5

21. Goto T, Kashiwagi E, Jiang G, Nagata Y, Teramoto Y, Baras AS, Yamashita S, Ito A, Arai Y, Miyamoto H (2020) Estrogen receptor- $\beta$ signaling induces cisplatin resistance in bladder cancer. Am J Cancer Res 10(8):2523-2534

22. Toska E, Osmanbeyoglu HU, Castel P, Chan C, Hendrickson RC, Elkabets M, Dickler MN, Scaltriti M, Leslie CS, Armstrong SA, Baselga J (2017) PI3K pathway regulates ER-dependent transcription in breast cancer through the epigenetic regulator KMT2D. Science 355(6331):1324-1330. doi:10.1126/science.aah6893

23. Toska E, Castel P, Chhangawala S, Arruabarrena-Aristorena A, Chan C, Hristidis VC, Cocco E, Sallaku M, Xu G, Park J, Minuesa G, Shifman SG, Socci ND, Koche R, Leslie CS, Scaltriti M, Baselga J (2019) PI3K Inhibition Activates SGK1 via a Feedback Loop to Promote Chromatin-Based Regulation of ERDependent Gene Expression. Cell Rep 27(1):294-306 e295. doi:10.1016/j.celrep.2019.02.111

24. Ao X, Ding W, Ge H, Zhang Y, Ding D, Liu Y (2020) PBX1 is a valuable prognostic biomarker for patients with breast cancer. Experimental therapeutic medicine 20(1):385-394. doi:10.3892/etm.2020.8705

25. Hayashi T, Seiler R, Oo HZ, J?Ger W, Moskalev I, Awrey S, Dejima T, Todenh?Fer T, Li N, Fazli L (2015) Targeting HER2 with T-DM1, an Antibody Cytotoxic Drug Conjugate, is Effective in HER2 Over Expressing Bladder Cancer. Journal of Urology:1120-1131

26. Chen W-m, Ming-de Huang D-pS, Kong R, Xu T-p, Xia R, Zhang E-b, Shu Y-q (2016) Long intergenic non-coding RNA 00152 promotes tumor cell cycle progression by binding to EZH2 and repressing p15 and p21 in gastric cancer. Oncotarget 7(9):9773

27. Lu H, Ju DD, Yang GD, Zhu LY, Yang XM, Li J, Song WW, Wang JH, Zhang CC, Zhang ZG, Zhang R (2019) Targeting cancer stem cell signature gene SMOC-2 Overcomes chemoresistance and inhibits cell proliferation of endometrial carcinoma. EBioMedicine 40:276-289. doi:10.1016/j.ebiom.2018.12.044

28. Zhang HH, Huang B, Cao YH, Li Q, Xu HF (2017) Role of 5-Aza-CdR in mitomycin-C chemosensitivity of T24 bladder cancer cells. Oncol Lett 14(5):5652-5656. doi:10.3892/ol.2017.6853 
29. Godoy G, Gakis G, Smith CL, Fahmy O (2016) Effects of Androgen and Estrogen Receptor Signaling Pathways on Bladder Cancer Initiation and Progression. Bladder Cancer 2(2):127-137. doi:10.3233/BLC-160052

30. Chaffer CL, Brennan JP, Slavin JL, Blick T, Thompson EW, Williams ED (2006) Mesenchymal-toepithelial transition facilitates bladder cancer metastasis: role of fibroblast growth factor receptor-2. Cancer research 66(23):11271-11278

31. Gugnoni M, Sancisi V, Gandolfi G, Manzotti G, Ragazzi M, Giordano D, Tamagnini I, Tigano M, Frasoldati A, Piana S, Ciarrocchi A (2017) Cadherin-6 promotes EMT and cancer metastasis by restraining autophagy. Oncogene 36(5):667-677. doi:10.1038/onc.2016.237

32. Li S, Cong X, Gao H, Lan X, Li Z, Wang W, Song S, Wang Y, Li C, Zhang H, Zhao Y, Xue Y (2019) Tumor-associated neutrophils induce EMT by IL-17a to promote migration and invasion in gastric cancer cells. J Exp Clin Cancer Res 38(1):6. doi:10.1186/s13046-018-1003-0

33. Risolino M, Mandia N, lavarone F, Dardaei L, Longobardi E, Fernandez S, Talotta F, Bianchi F, Pisati F, Spaggiari L, Harter PN, Mittelbronn M, Schulte D, Incoronato M, Di Fiore PP, Blasi F, Verde P (2014) Transcription factor PREP1 induces EMT and metastasis by controlling the TGF- $\beta$-SMAD3 pathway in non-small cell lung adenocarcinoma. Proc Natl Acad Sci U S A 111(36):E3775-E3784. doi:10.1073/pnas.1407074111

34. Zhu X, Wei L, Bai Y, Wu S, Han S (2017) FoxC1 promotes epithelial-mesenchymal transition through PBX1 dependent transactivation of ZEB2 in esophageal cancer. Am J Cancer Res 7(8):1642-1653

35. Toska E, Osmanbeyoglu HU, Castel P, Chan C, Baselga J (2017) PI3K pathway regulates ERdependent transcription in breast cancer through the epigenetic regulator KMT2D. Science 355(6331):1324-1330

36. Zhuang C, Ma Q, Zhuang C, Ye J, Zhang F, Gui Y (2019) LncRNA GClnc1 promotes proliferation and invasion of bladder cancer through activation of MYC. FASEB journal: official publication of the Federation of American Societies for Experimental Biology 33(10):11045-11059. doi:10.1096/fj.201900078RR

37. Long Y, Wu Z, Yang X, Chen L, Han Z, Zhang Y, Liu J, Liu W, Liu X (2016) MicroRNA-101 inhibits the proliferation and invasion of bladder cancer cells via targeting c-FOS. Mol Med Rep 14(3):26512656. doi:10.3892/mmr.2016.5534

38. Hsu I, Vitkus S, Da J, Yeh S (2013) Role of oestrogen receptors in bladder cancer development. Nature reviews Urology 10(6):317-326. doi:10.1038/nrurol.2013.53

39. Wolpert BJ, Amr S, Ezzat S, Saleh D, Gouda I, Loay I, Hifnawy T, Mikhail NN, Abdel-Hamid M, Zhan M, Zheng YL, Squibb K, Abdel-Aziz MA, Zaghloul M, Khaled H, Loffredo CA (2010) Estrogen exposure and bladder cancer risk in Egyptian women. Maturitas 67(4):353-357. doi:10.1016/j.maturitas.2010.07.014

40. Miyamoto H, Yang Z, Chen YT, Ishiguro H, Uemura H, Kubota Y, Nagashima Y, Chang YJ, Hu YC, Tsai MY, Yeh S, Messing EM, Chang C (2007) Promotion of bladder cancer development and progression by androgen receptor signals. J Natl Cancer Inst 99(7):558-568. doi:10.1093/jnci/djk113 
41. Izumi K, Zheng Y, Hsu JW, Chang C, Miyamoto H (2013) Androgen receptor signals regulate UDPglucuronosyltransferases in the urinary bladder: a potential mechanism of androgen-induced bladder carcinogenesis. Molecular carcinogenesis 52(2):94-102. doi:10.1002/mc.21833

42. Ding M, Liu Y, Li J, Yao L, Liao X, Xie H, Yang K, Zhou Q, Liu Y, Huang W, Cai Z (2018) Oestrogen promotes tumorigenesis of bladder cancer by inducing the enhancer RNA-eGREB1. J Cell Mol Med 22(12):5919-5927. doi:10.1111/jcmm.13861

43. Sonpavde G, Okuno N, Weiss H, Yu J, Shen SS, Younes M, Jian W, Lerner SP, Smith CL (2007) Efficacy of selective estrogen receptor modulators in nude mice bearing human transitional cell carcinoma. Urology 69(6):1221-1226. doi:10.1016/j.urology.2007.02.041

44. Shen SS, Smith CL, Hsieh JT, Yu J, Kim IY, Jian W, Sonpavde G, Ayala GE, Younes M, Lerner SP (2006) Expression of estrogen receptors-alpha and -beta in bladder cancer cell lines and human bladder tumor tissue. Cancer 106(12):2610-2616. doi:10.1002/cncr.21945

45. Su Y, Yang W, Jiang N, Shi J, Chen L, Zhong G, Bi J, Dong W, Wang Q, Wang C (2019) Hypoxiaelevated circELP3 contributes to bladder cancer progression and cisplatin resistance. Int J Biol Sci 15(2):441-452

46. Zhang Y, Zhi W, Yu J, Jia ZS, Wang C, Wei HF, Zhi WC, Jin Y (2012) Cancer stem-like cells contribute to cisplatin resistance and progression in bladder cancer. Cancer Lett 322(1):70-77

47. Ghosh S (2019) Cisplatin: The first metal based anticancer drug. Bioorg Chem 88:102925. doi:10.1016/j.bioorg.2019.102925

48. Sekino Y, Sakamoto N, Ishikawa A, Honma R, Yasui W (2019) Transcribed ultraconserved region Uc.63 + promotes resistance to cisplatin through regulation of androgen receptor signaling in bladder cancer. Oncol Rep 41(5):3111-3118

49. Fang CH, Lin YT, Liang CM, Liang SM (2020) A novel c-Kit/phospho-prohibitin axis enhances ovarian cancer stemness and chemoresistance via Notch3-PBX1 and $\beta$-catenin-ABCG2 signaling. Journal of Biomedical Science 27 (1)

50. Goto T, Kashiwagi E, Jiang G, Nagata Y, Miyamoto H Estrogen receptor- $\beta$ signaling induces cisplatin resistance in bladder cancer. American journal of cancer research 10 (8):2523-2534

\section{Figures}


A
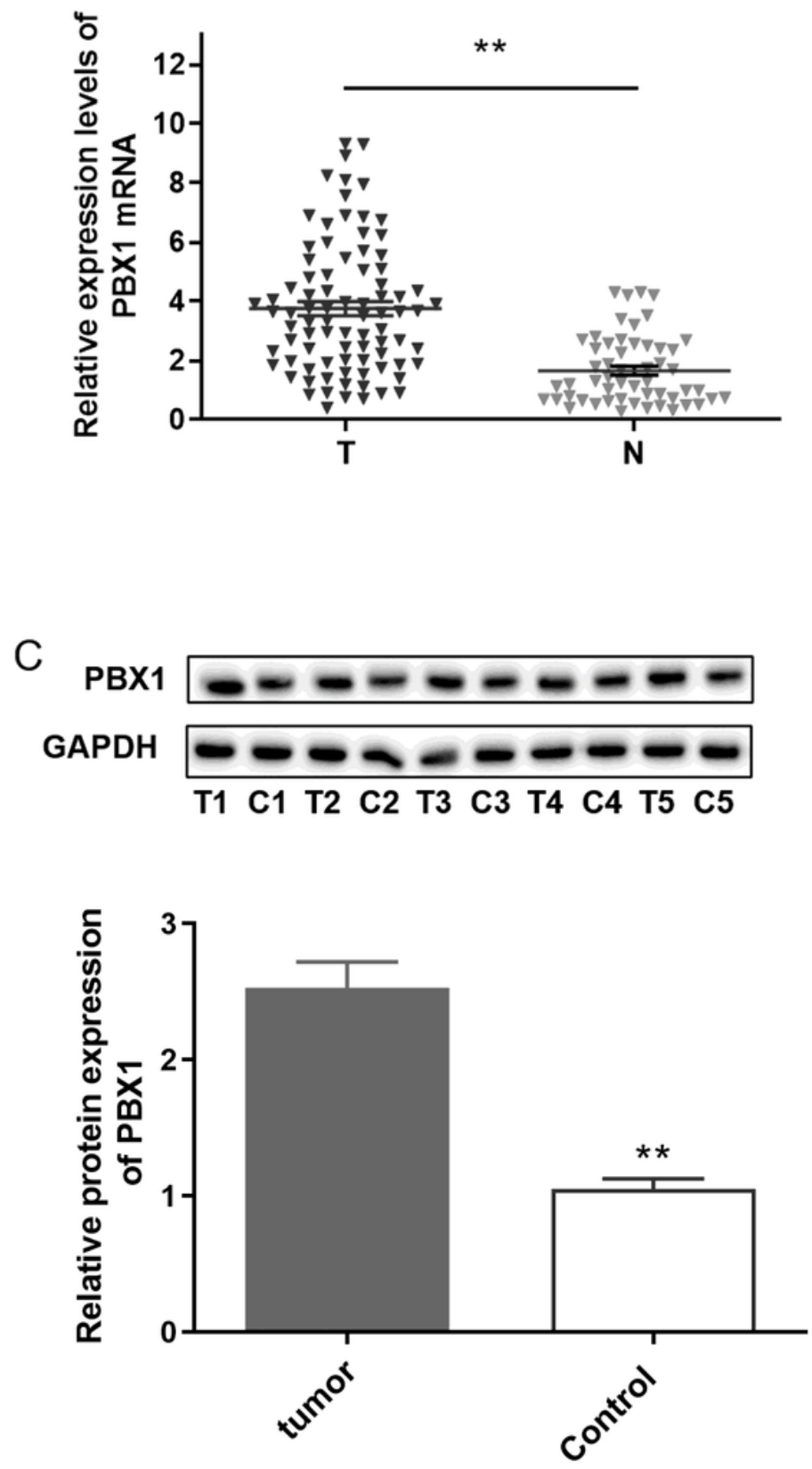

B

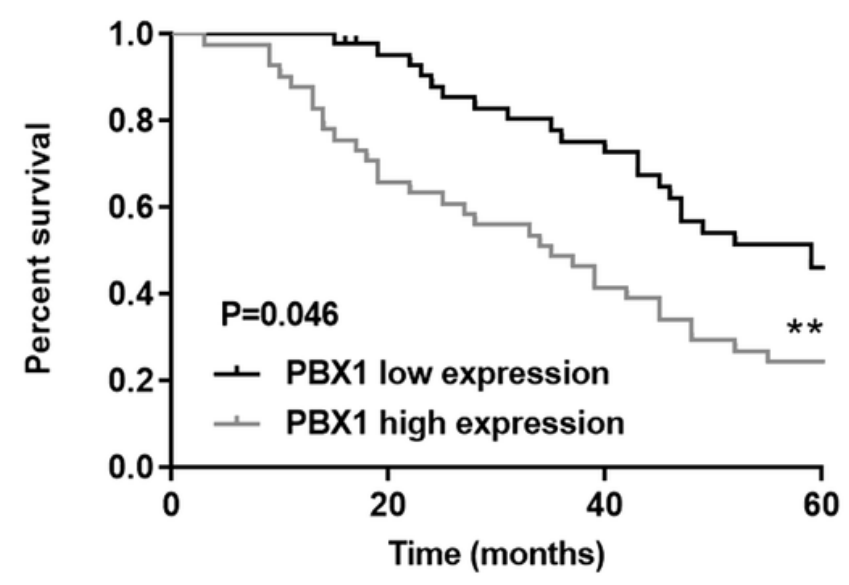

D
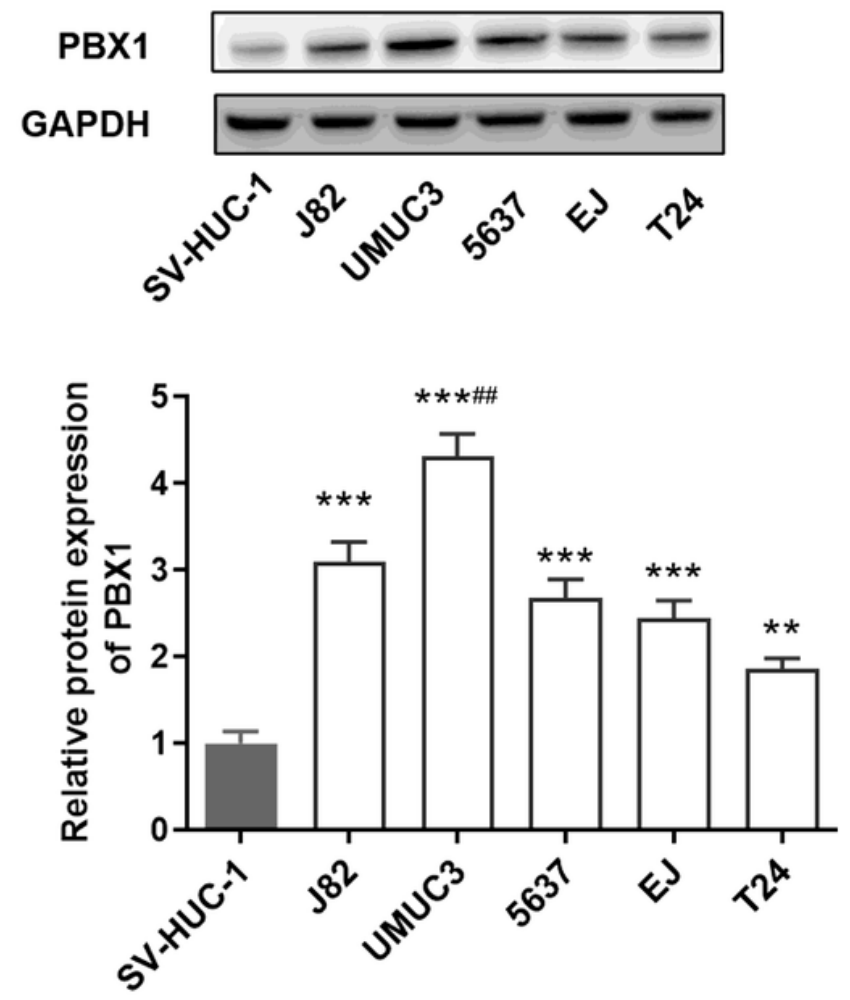

Figure 1

PBX1 was high expressed in BCa patients and cell lines, and related to poor prognosis. A. The mRNA expression of PBX1 was measured through RT-qPCR. T: muscle-invasive BCa tissues ( $n=85)$; N: un-paired non-tumor bladder tissues $(n=53), * * P<0.01$. B. Kaplan-Meier survival curves of $B C a$ patients with high and low PBX1 expression value (Values are expressed as median), ${ }^{\star *} \mathrm{P}<0.01$. C. Five pairs of $\mathrm{BCa}$ samples were subject to Western blotting analysis of PBX1 expression. T1-T5: bladder tumor tissues; C1C5: paired non-tumor bladder tissues. ${ }^{\star \star} \mathrm{P}<0.01$. D. The expression of PBX1 protein in normal bladder cell 
line (SV-HUC-1) and BCa cell lines were detected by Western blotting. ${ }^{*} \mathrm{P}<0.01$ and $* \star \star ~ P<0.005$ compared with SV-HUC-1 cells; \#\# P 0.01 compared with J82 cells.

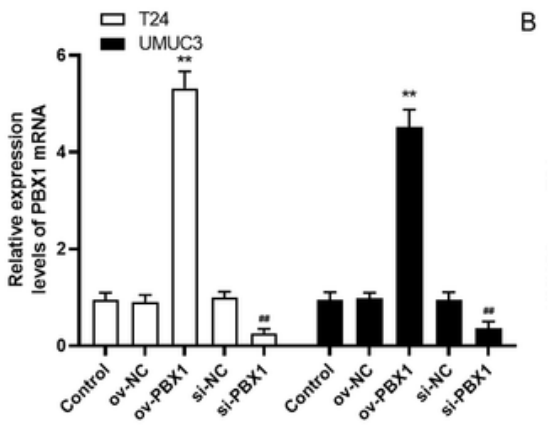

D

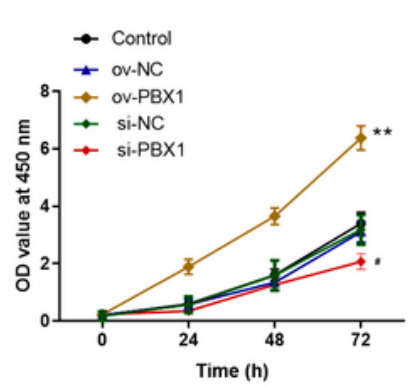

G

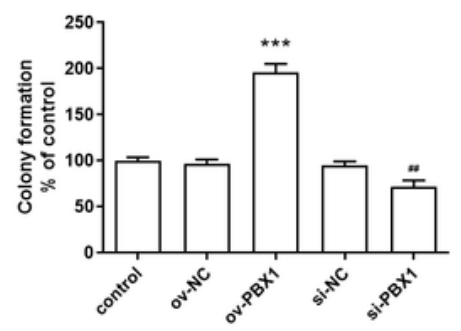

$B$

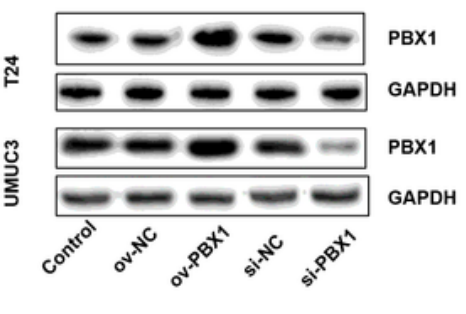

$\mathrm{E}$

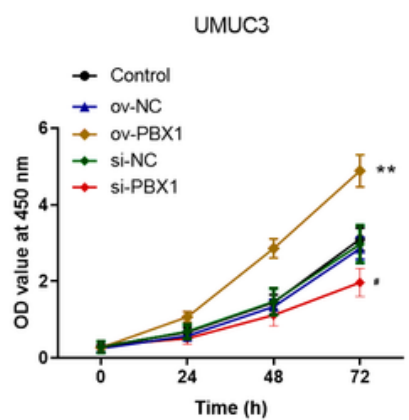

$\mathrm{H}$

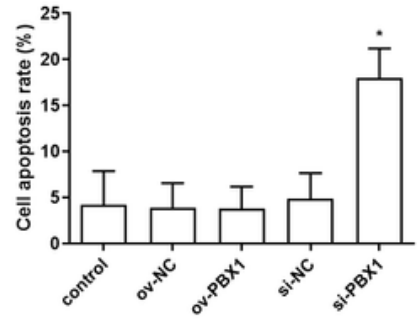

C

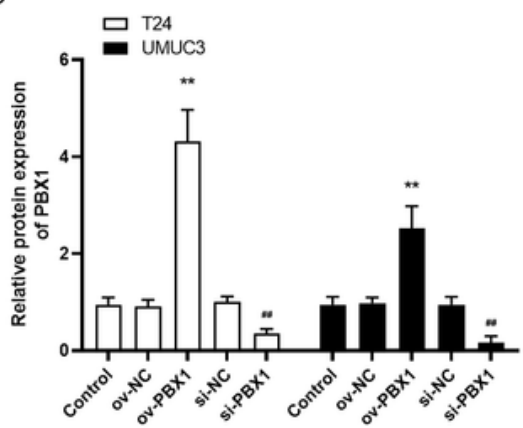

$\mathrm{F}$

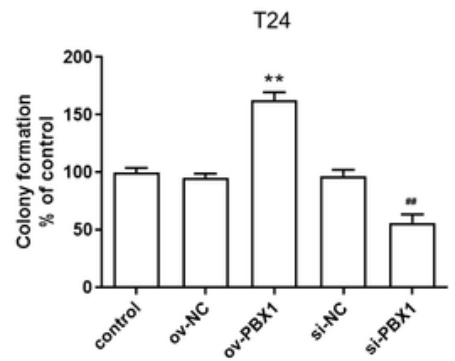

UMUC3

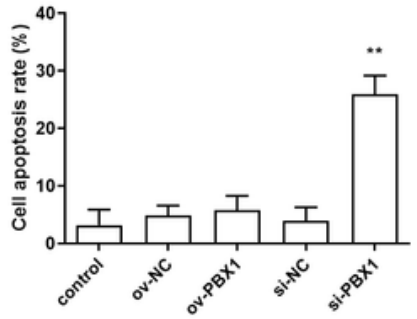

$$
\text { ง }
$$
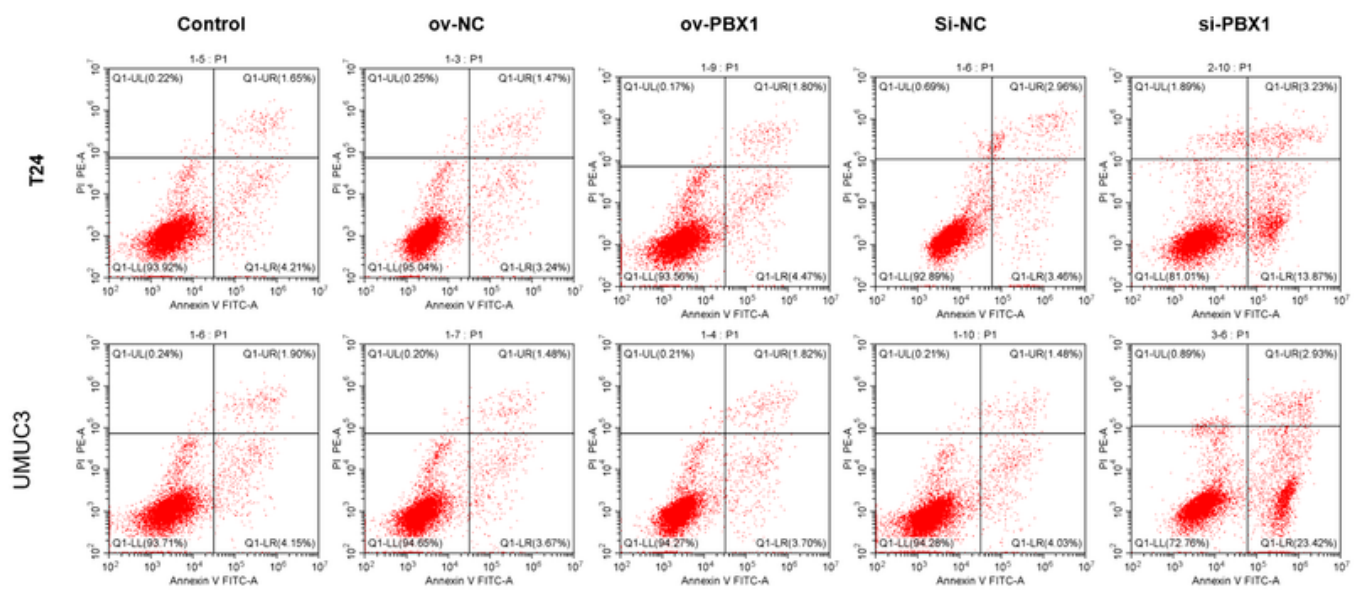

Figure 2

Effect of PBX1 overexpression and inhibition on the growth, and apoptosis of BCa cells. A-C. Transfection efficiency of ov-PBX1 and si-PBX1 in T24 and UMUC3 cells were detected by RT-qPCR and Western blotting. ov-PBX1: overexpression vectors of PBX1; si-PBX1: siRNA of PBX1. D-G. Cell proliferation was 
detected by CCK-8 assay kit (D and E) and colony formation assay ( $\mathrm{F}$ and $\mathrm{G}$ ). $\mathrm{H}$-J. Cell apoptosis was

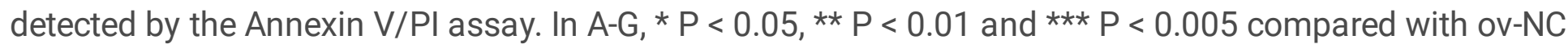
group; \# $\mathrm{P}<0.05$ and \#\# $\mathrm{P}<0.01$ compared with si-NC group. In $\mathrm{H}-\mathrm{J}$, ${ }^{*} \mathrm{P}<0.05$ and $* \star \mathrm{P}<0.01$ compared with si-NC group.

A

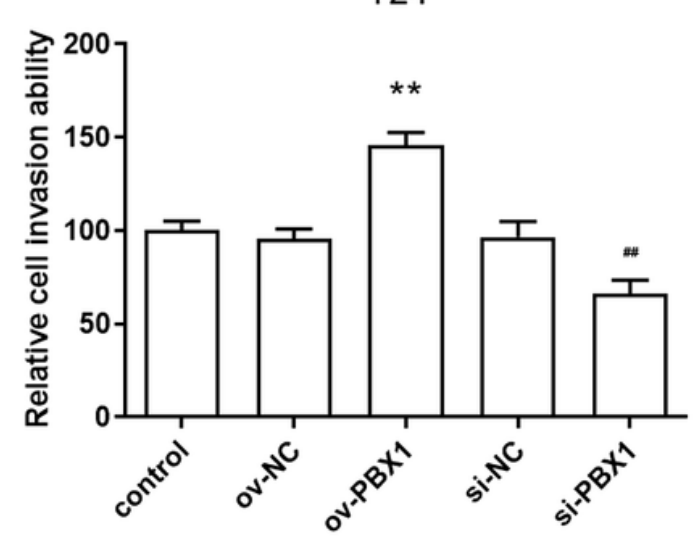

C

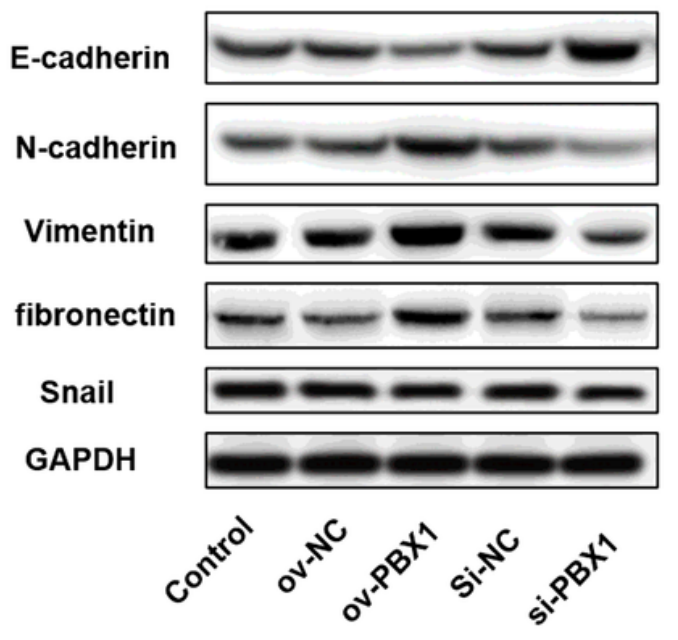

B
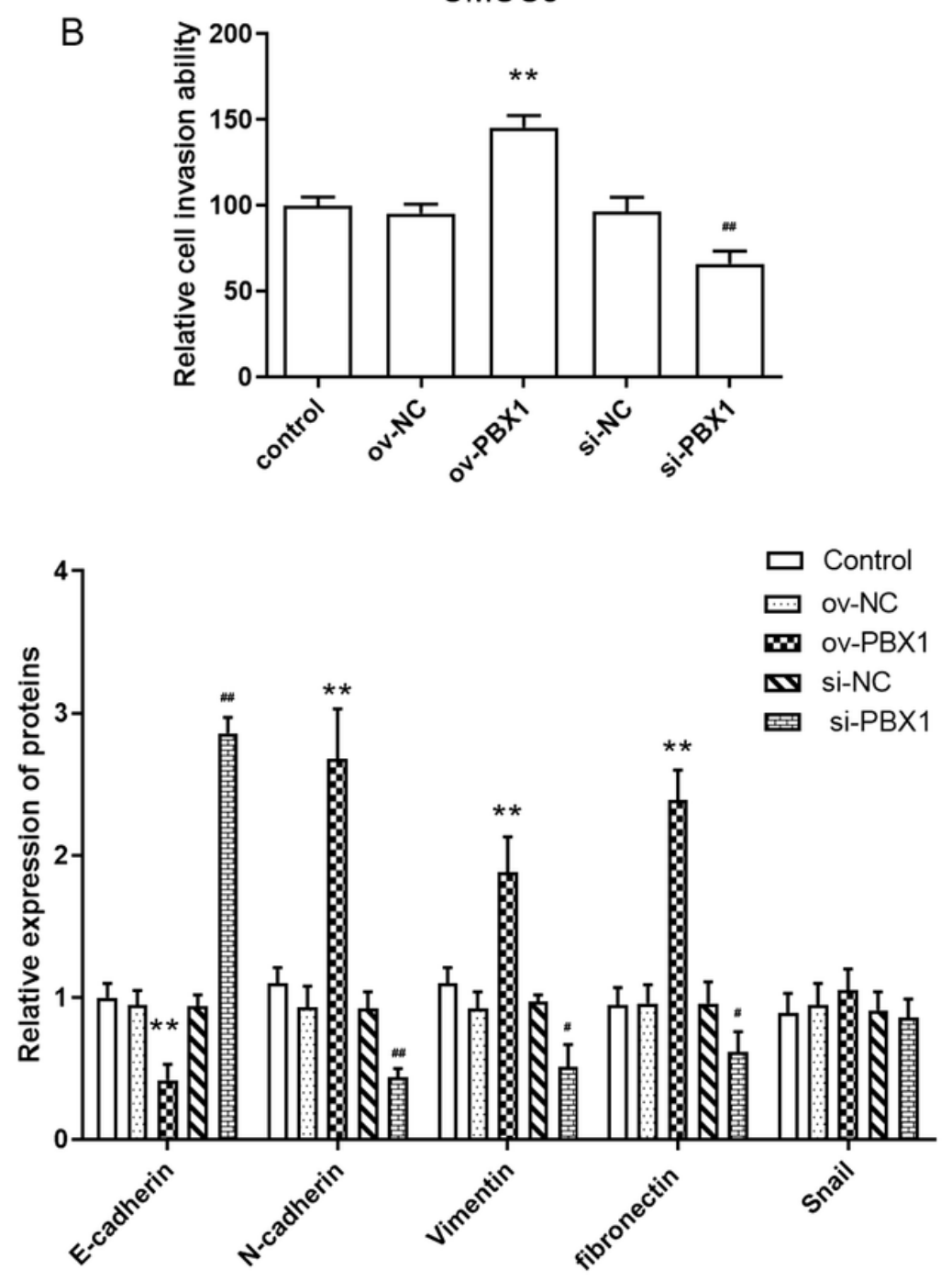

\section{Figure 3}

The effect of PBX1 on the migration and EMT activity of BCa cells. A and B. Cell invasion ability of T24 and UMUC3 cells were measured through Transwell assay. C. The expression of EMT biomarkers Ecadherin, N-cadherin, Vimentin, fibronectin and Snail in T24 cells were detected through Western blotting. ** $\mathrm{P}<0.01$ compared with ov-NC group; \# $\mathrm{P}<0.05$ and \#\# $\mathrm{P}<0.01$ compared with si-NC group. 
A

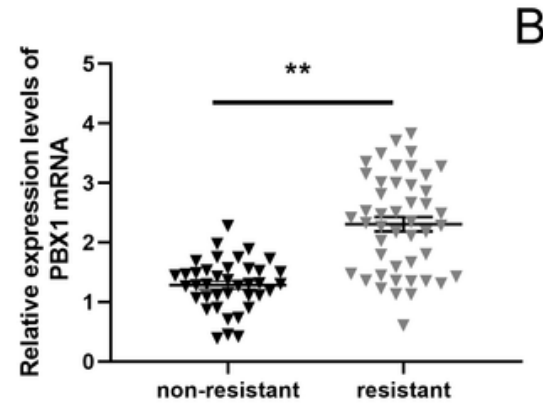

C

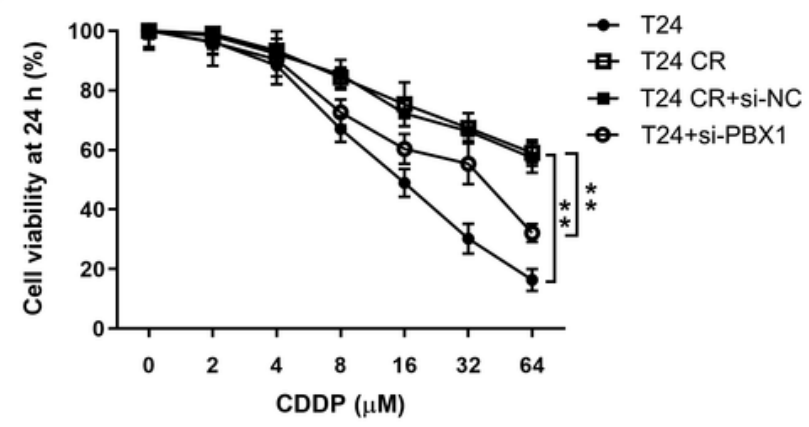

D

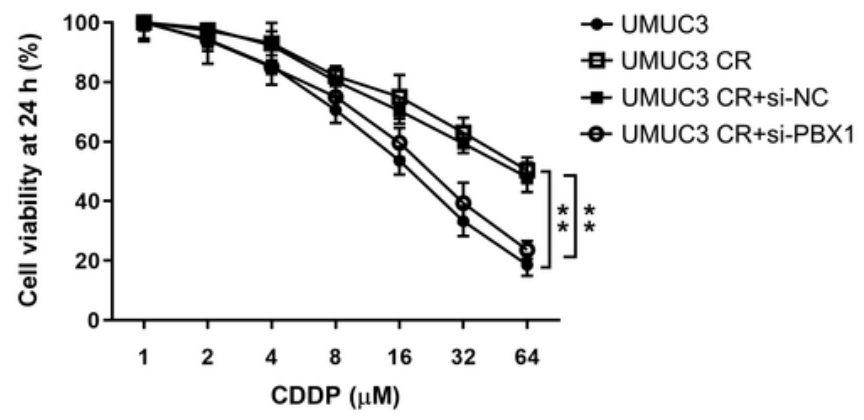

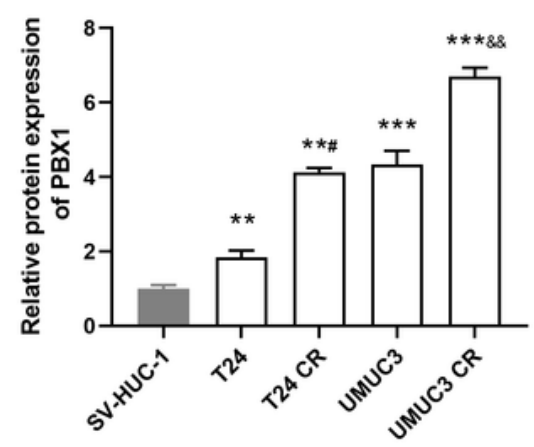
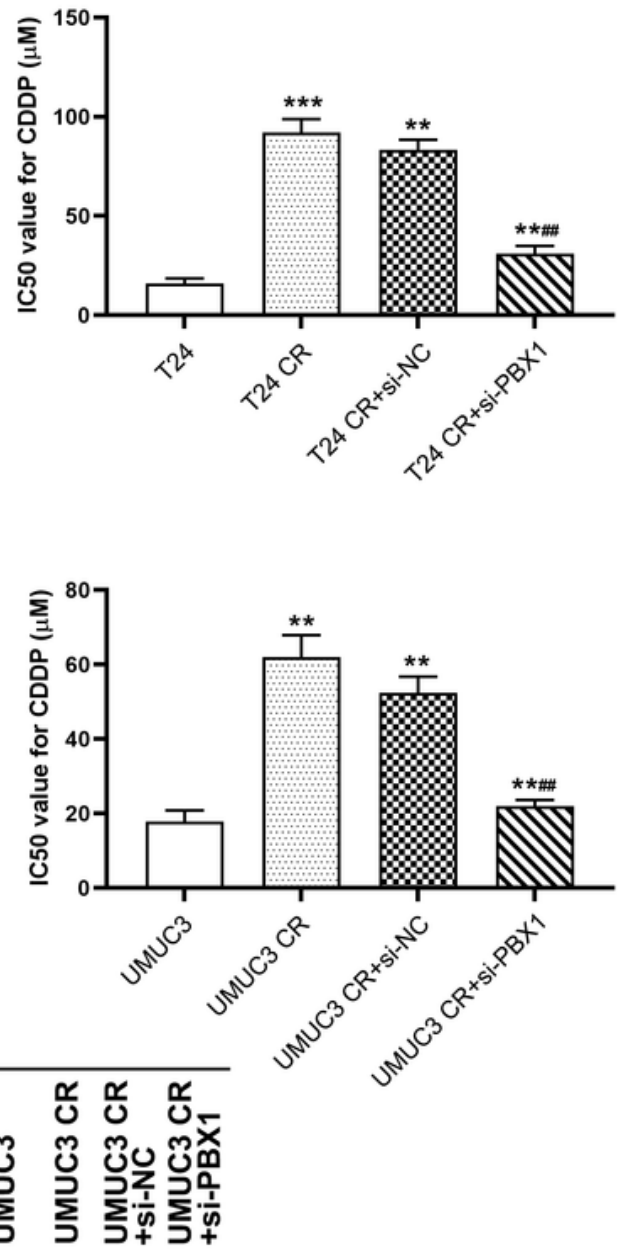

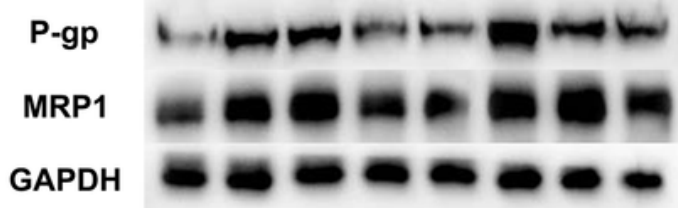

\section{Figure 4}

Inhibition of PBX1 suppressed CDDP resistance of BCa cells. A and B. The expression levels of PBX1 were measured by RT-qPCR in non-resistant and resistant BCa patients' tissues, as well as BCa cells. In A, ** $P<0.01$; in $B$, ** $P<0.01$ versus SV-HUC-1, \#P<0.01 versus T24, \&\& $P<0.01$ versus UMUC3. $C$ and $D$. Cell viability of normal and CDDP resistant $B C a$ cells was evaluated by CCK-8 methods at $24 \mathrm{~h}$; $* * \mathrm{P}<$ 
0.01; \#\# P $<0.01$ versus CDDP + si-NC group. E. The protein expressions of P-gp and MRP1 were detected by western blotting assay.

A

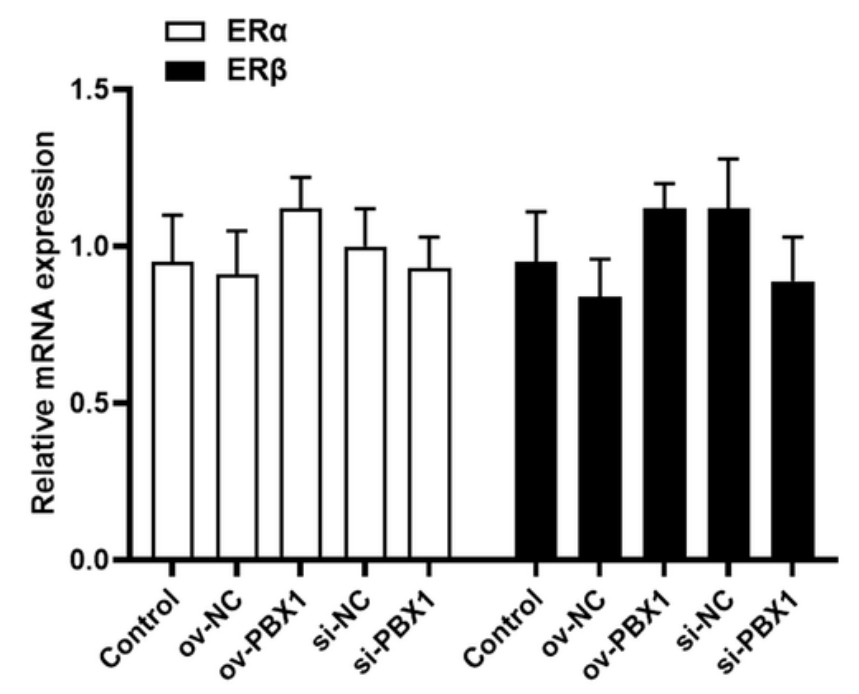

B

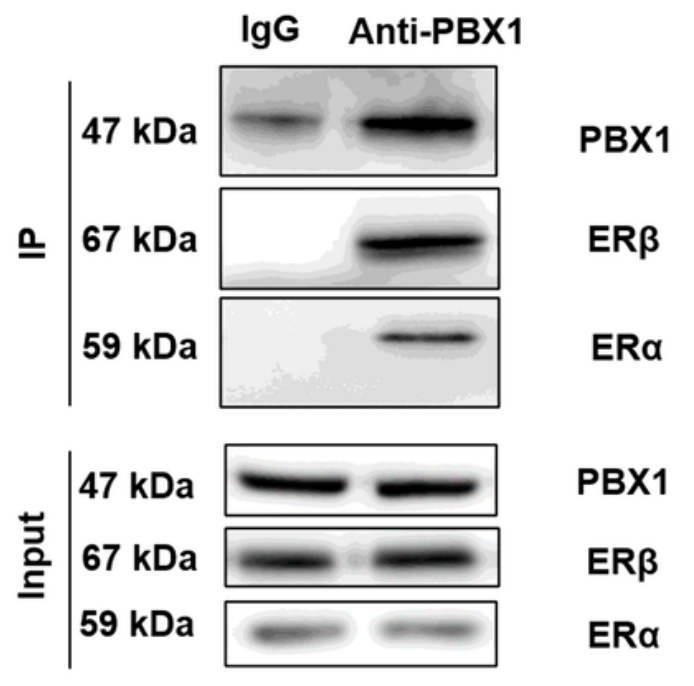

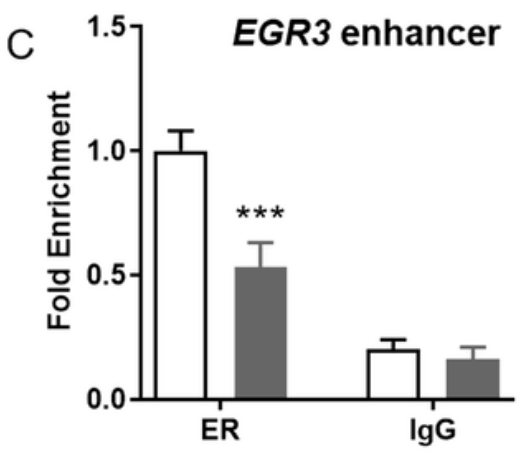
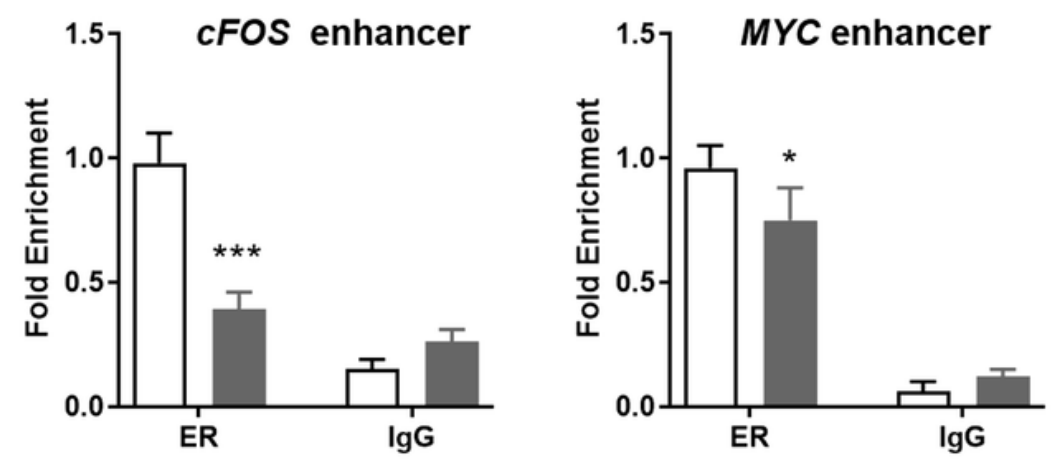

$\square$ si-NC

si-PBX1

EGR3

D

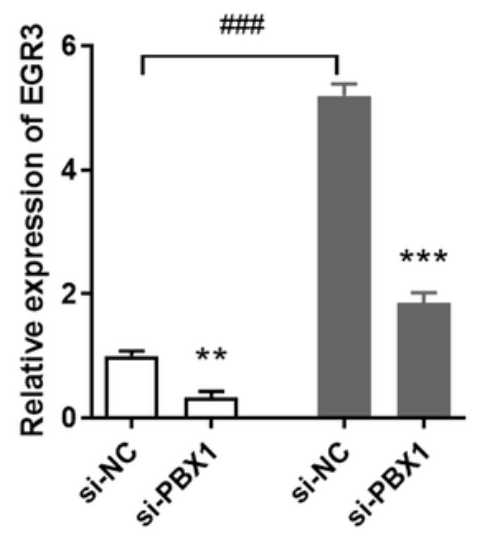

cFOS

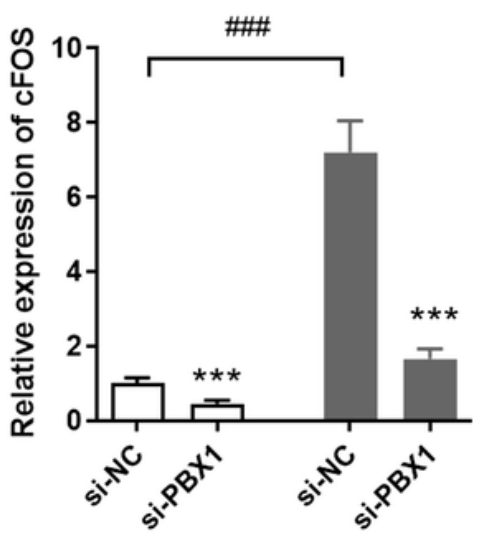

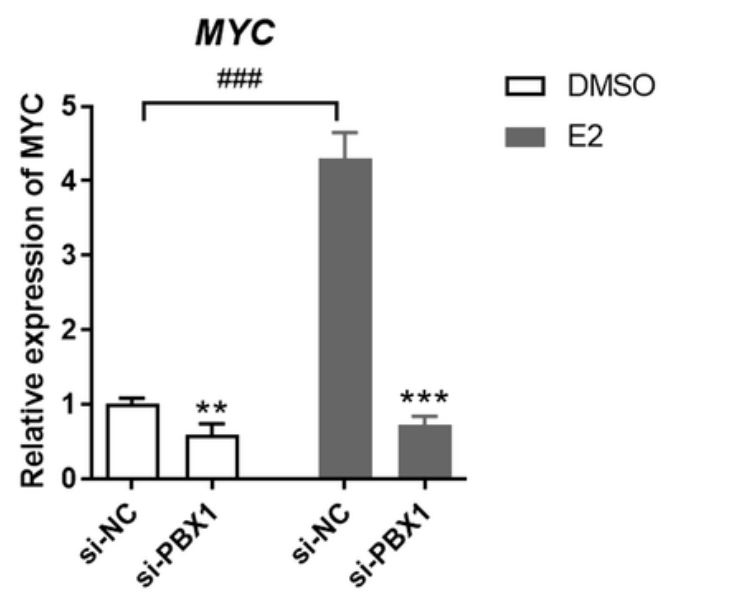

Figure 5

Inhibition of PBX1 suppressed the ER-dependent transcription. A. The expression levels of ERa and ER $\beta$ were measured by RT-qPCR in T24 cells after PBX1 overexpression or inhibition. B. CO-IP was performed in T24 cells. IgG, immunoglobulin G. C. ER occupancy in the enhancer of EGR3, cFOS and MYC in T24 
cells was measured by ChIP-qPCR after knockdown of PBX1. Values were expressed as fold enrichment (the mean percentage of input enrichment of the candidate gene/a control gene). D. The mRNA levels of EGR3, cFOS and MYC were measured by RT-qPCR in T24 cells. Cells were maintained in estrogen-free media for three days, and then treated by DMSO or E2 (estrogen; $100 \mu \mathrm{M}$ ) for 24 hours. ${ }^{*} \mathrm{P}<0.05$, $* \star \mathrm{P}<$ 0.01 and $* * * \mathrm{P}<0.005$ versus si-NC group; \#\#\# $\mathrm{P}<0.005$.

A

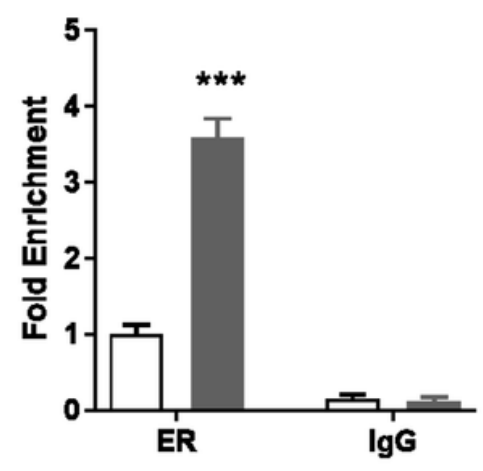

B

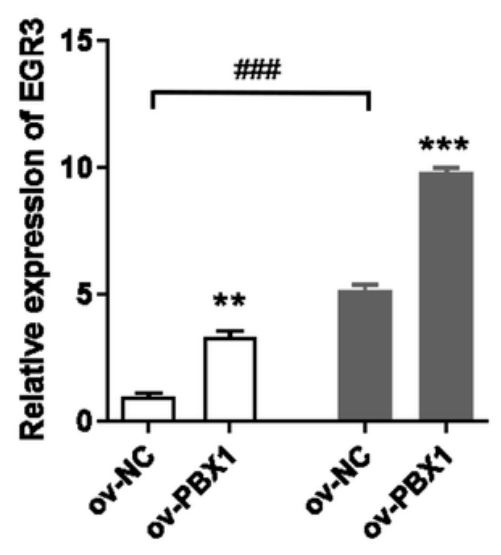

cFOS enhancer
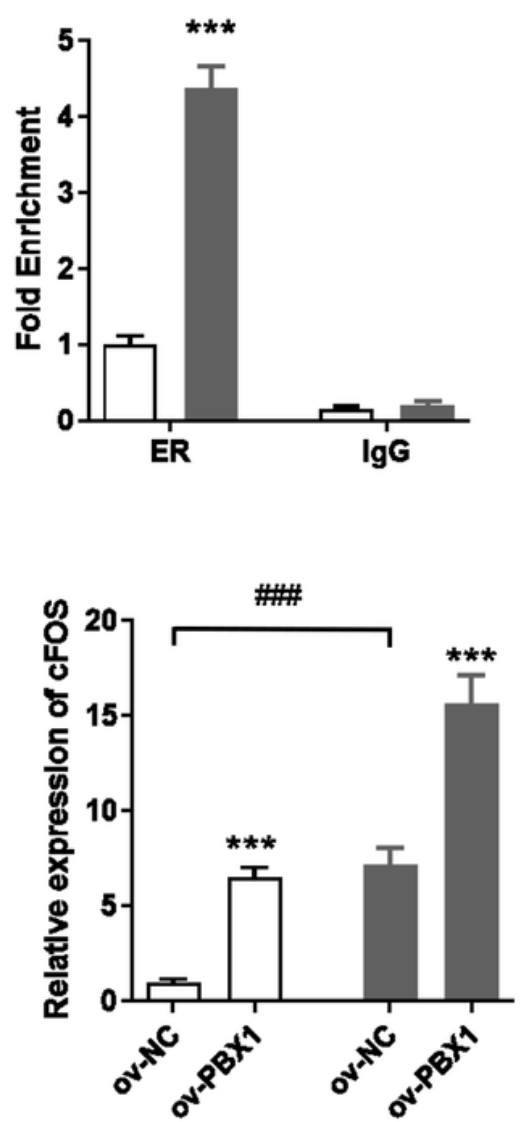

MYC enhancer
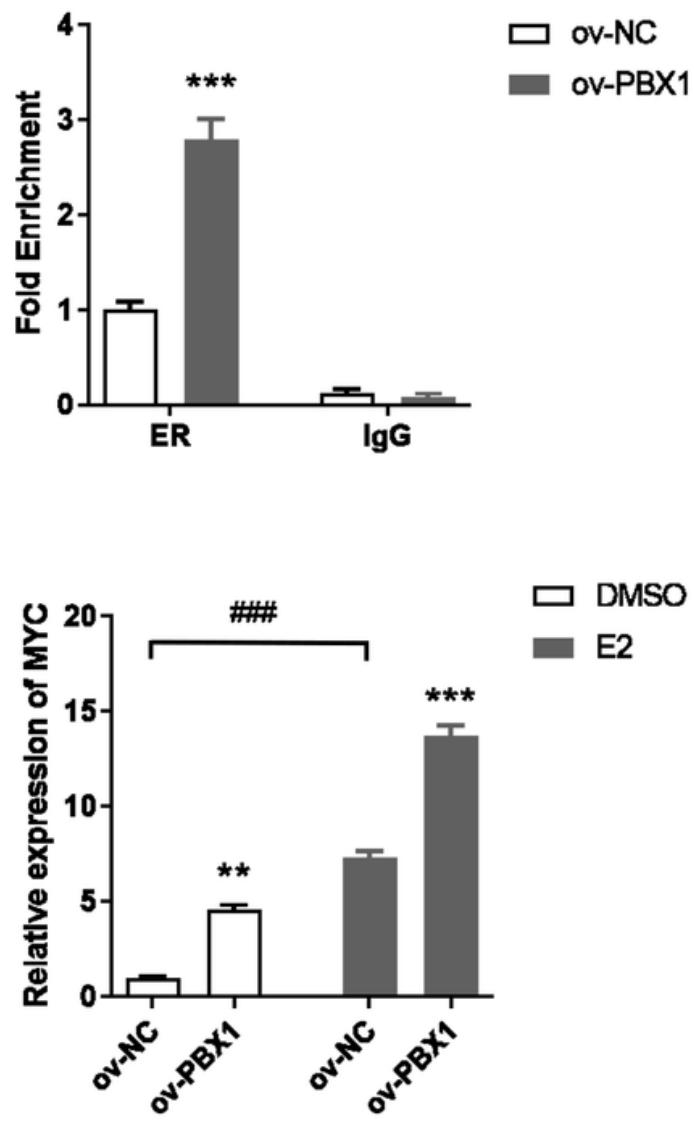

Figure 6

Overexpression of PBX1 promoted the ER-dependent transcription. A. ChIP-qPCR assay of ER and control IgG binding at the candidate target genes in T24 cells after overexpression of PBX1. B. The expression of EGR3, cFOS and MYC in T24 cells were measured through RT-qPCR. ** $\mathrm{P}<0.01$ and $* \star * P<0.005$ compared with ov-NC group; \#\#\# $\mathrm{P}<0.005$. 

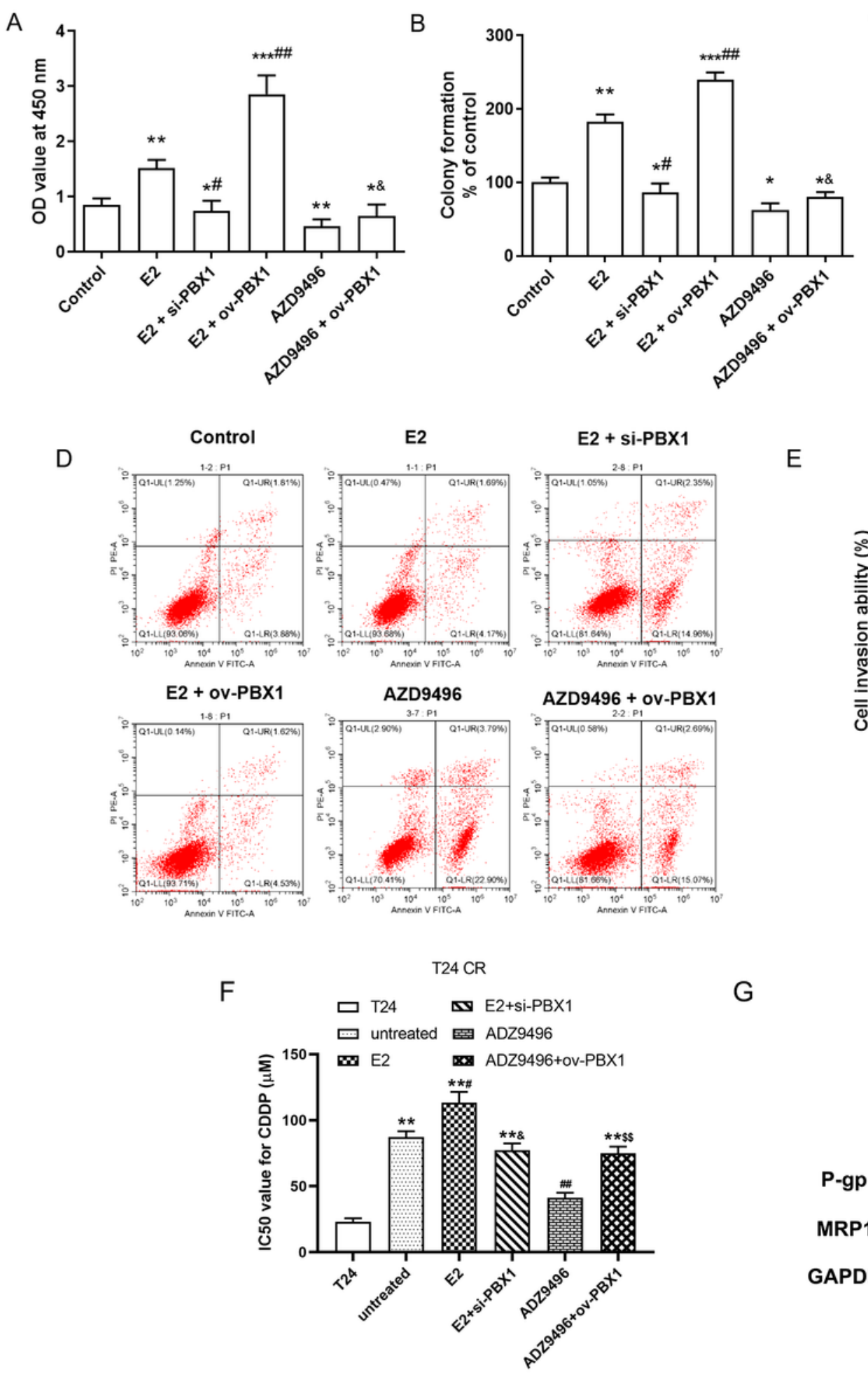

G

E
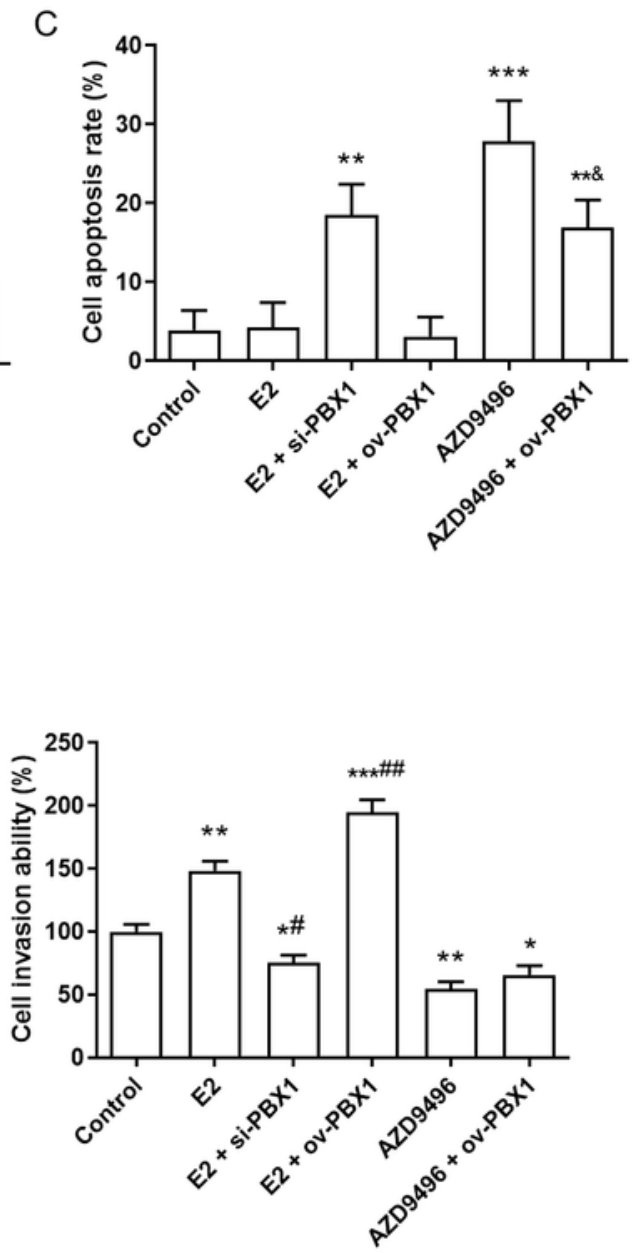

\section{Figure 7}

Effect of PBX1 overexpression or inhibition on E2 or ER antagonist treated T24 cells. Cell proliferation (A), colony formation (B), cell apoptosis ( $C$ and $D$ ) and cell invasion (E) of T24 cells were measured. Cells were treated with E2 $(100 \mu \mathrm{M})$ or ER antagonist AZD9496 $(100 \mathrm{nM})$ for $24 \mathrm{~h}$ upon PBX1 overexpression or inhibition. F. IC50 values of cultured cells were evaluated. In $A-E, * P<0.05, \star \star P<0.01$ and $* \star \star P<0.005$ compared with the control group; \# P $<0.05$ and \#\# $\mathrm{P}<0.01$ compared with E2 group; \& $\mathrm{P}<0.05$ 
compared with AZD9496 group. In $\mathrm{F}$, ** $\mathrm{P}<0.01$ compared with T24 group; \# $\mathrm{P}<0.05$ and \#\# $\mathrm{P}<0.01$ compared with untreated T24 CR group; \& $\mathrm{P}<0.05$ compared with E2 group; \$ $\mathrm{P}<0.01$ compared with ADZ9496 group. 